\title{
Plant Regeneration from Leaf Derived Callus of Stevia rebaudiana Bertoni
}

\author{
B. Janarthanam, M. Gopalakrishnan, G. Lakshmi Sai \\ and T. Sekar* \\ Plant Tissue Culture Laboratory, P.G. E Research Department of Botany, \\ Pachaiyappa's College, Chennai-600 030, India
}

Key words: Stevia rebaudiana, Leaf explant, Callus culture, Micropropagation

\begin{abstract}
Juvenile leaf explants of Stevia rebaudiana Bertoni produced maximum callus than the nodal explants cultured on MS containing $11.31 \mu \mathrm{M} 2$, 4-D and 2.22 $\mu \mathrm{M}$ BAP. Callus transferred to MS supplemented with $4.44 \mu \mathrm{M}$ BA and $1.34 \mu \mathrm{M}$ NAA showed better growth response and produced $14.0 \pm 1.0$ shoots with an average length of $5.6 \pm 0.1 \mathrm{~cm}$ after 28 days. All plantlets produced profuse rooting within 25 days after transfer to half strength of MS basal medium supplemented with $2.46 \mu \mathrm{M}$ IBA. Rooted plantlets were transferred for hardening, with $90 \%$ of plantlets successfully established in the field.
\end{abstract}

\section{Introduction}

Stevia rebaudiana Bertoni a perennial shrub belongs to Asteraceae. It is grown commercially in many parts of Brazil, Paraguay, Central America, Israel, Thailand, Korea and China (Soejarto et al. 1983). Its leaves and extracts are widely used as health food in tea bags, tablets, soft drinks, sea food, dessert items and confectionaries in recent years in Japan and South America (Fujita and Edahiro 1979, Nabors and Gelardi 1991). The leaves of Stevia are the source of the diterpene glycosides, stevioside and rebaudioside, which are reported to be 100 300 times sweeter than sucrose (Ishima and Katayama 1986, Tanaka 1982). Use of stevioside as a natural sweetener has been reported to be safe (Geuns 2004). The seeds of Stevia show a very low germination percentage (Goettemoeller and Ching 1999) and propagation by seed does not produce homogenous populations, resulting in great variability in important feature like sweetening level and composition (Tamura et at. 1984). Vegetative propagation is also limited by small number of individuals that can be obtained simultaneously from a single plant (Sakaguchi and Kan 1982). With the above mentioned difficulties, tissue culture has been the alternative for rapid mass propagation of Stevia.

*Author for correspondence. <tsekar_2005@yahoo.com>. 
Earlier in vitro propagation of Stevia has been attempted through different explants: viz. leaf, shootips and axillary buds (Ferreira and Handro 1988, Ferreira and Handro 1987, Patil et al. 1996, Janarthanam and Kanimozhi 2005). However, callus regeneration from leaf explants has not been reported so far. Leaf tissues are reported to be more organogenic in various plants, such as Coleus forskohlii, Cajanus cajan, Gloriosa superba. The present study aims at developing a simple, rapid, economical, and high frequency regeneration protocol from leaf explants of $S$. rebaudiana so as to give rise to true-to-type clones for potential application in large-scale propagation.

\section{Materials and Methods}

Healthy Stevia rebaudiana Bertoni plants were obtained from RICHSAAI, Solar nursery Chennai and were raised in pots containing soil and farm yard manure (1 : 1) under greenhouse condition at P.G. \& Research Department of Botany, Pachaiyappa's College, Chennai-600 030, India. Leaf explant was collected from potted plants and processed for aseptic culture. Explants were surface sterilized by cleaning thoroughly under running tap water for ten min, washed with a solution of Tween 20 (two drops in $100 \mathrm{ml}$ of water) for one min, and again washed with sterile distilled water. The cleaned explants were finally treated with $\mathrm{HgCl}_{2}(0.1 \%)$ for three - four min under aseptic conditions and washed five times with sterile distilled water to remove traces of $\mathrm{HgCl}_{2}$. After surface sterilization, the explants were cut into small pieces and inoculated in MS supplemented with 2, 4-D $(0.45,2.26,4.52,11.31$ and $22.62 \mu \mathrm{M})$; NAA $(1.34,2.69$, 5.37, 13.43 and $26.85 \mu \mathrm{M})$ and BAP $(1.11,2.22,4.44,8.8813 .32$ and $22.20 \mu \mathrm{M})$ in different concentrations and combinations for the production of callus. The primary callus obtained from the leaf explant was subcultured in the same medium. For shoot multiplication, $0.5 \mathrm{~g}$ of 24 to 28 - days old callus was transferred to MS supplemented with different concentrations and combinations of BAP $(0.56-22.20 \mu \mathrm{M})$ and NAA $(0.54-5.36 \mu \mathrm{M})$. After 35 days, the fully developed shootlets were transferred to half strength of MS basal medium supplemented with IBA $(0.49-2.46 \mu \mathrm{M})$ for root development. After a further 25 days, culture vessels containing the rooted plantlets were transferred to greenhouse under $60-70 \%$ humidity. The plantlets were fertigated with dilute MS basal media. After 15 days, the fully acclimatized plantlets were transferred to $6 \mathrm{~cm}$ pots containing red soil, vermiculite and farmyard manure $(1: 1: 1)$.

For all the above studies, MS basal medium containing 3\% w/v sucrose was used. All the plant growth regulators were filter-sterilized using a $0.2 \mu \mathrm{m}$ filter (Minisart ${ }^{\circledR}$, Sartorius, VivaScience AG, Hannover, Germany) before addition to culture media. The $\mathrm{pH}$ of the medium was adjusted to $5.6 \pm 0.2$, gelled with $0.9 \%$ agar (Hi media, India), and autoclaved at $121^{\circ} \mathrm{C}$ at 15 psi for 15 min. Cultures 
were maintained at $25 \pm 1^{\circ} \mathrm{C}$ under $16 \mathrm{~h}$ light and $8 \mathrm{~h}$ dark cycle. Lighting was provided using white cool fluorescent tubes of $40 \mu \mathrm{mol} / \mathrm{m}^{2} / \mathrm{s}$ light intensity. Each experiment was repeated three times and each treatment had six replicates. The data were subjected to ANOVA and means were performed by DMRT using SPSS (SPSS ver. 16.0).

\section{Results and Discussion}

Leaf and nodes explants of Stevia rebaudiana were cultured on MS supplemented with 2, 4-D or NAA in combination with $2.22 \mu \mathrm{M}$ BAP. Both 2, 4-D and NAA were effective at inducing callus formation when used in combination with BAP. While 2, 4-D generated higher frequencies of callus formation than NAA, the percentage response was not significantly different between BAP and NAA. Callus response varied between nodal and leaf explants with 60 and 80\%, respectively (Table 1, Fig. 1A). MS supplemented with BAP and 2, 4-D was more effective for inducing callus from leaf explants than supplementation with NAA and BAP. MS supplemented with $11.31 \mu \mathrm{M}$ of 2, 4-D and $2.22 \mu \mathrm{M}$ of BAP yielded two times more callus than the other media. Both friable and green compact calluses were observed where the callus was white and friable initially and later turned into compact nodular callus after prolonged incubation. Early callus formation from internode explants of $S$. rebaudiana was reported using MS containing $13.56 \mu \mathrm{M}$ 2, 4- D which gave maximum callus production (Uddin et al. 2006), whereas in the present study leaf explants produced maximum callus. The formation of early callus from leaf explant of Stevia rebaudiana in MS containing 2, 4-D and BAP supported the present finding (Ferreira and Handro 1988). The morphogenic callus generated from leaf segments after $24-28$ days was transferred to MS supplemented with different concentrations and combinations of BAP $(2.22-22.20 \mu \mathrm{M})$ and NAA $(2.69-26.85 \mu \mathrm{M})$. Callus demonstrated differential responses according to the hormonal concentration (Table 2), with shoot initiation observed three weeks after subculture. BAP has been considered to be most effective for the induction of shoot in plant tissue culture (Asamenew and Narayanaswamy 2000, Baskaran and Jayabalan 2005, Russell 1979). In the present study, BAP and NAA were not effective in inducing shoots when applied alone. Indeed, shoots were formed only when the medium was supplemented with BAP at $4.44 \mu \mathrm{M}$ in addition to NAA. Concentrations of this BAP above and below this level were ineffective for inducing de novo shoot regeneration (Table 2). When BAP was present at $4.44 \mu \mathrm{M}$, addition of all levels of NAA tested was effective for stimulating regeneration of shoots. However, $1.34 \mu \mathrm{M}$ of NAA was most effective for inducing $80 \%$ of the callus to form shoots and induced greatest number of shoots $(14.0 \pm 1.0)$ per explant. Addition of higher amounts of NAA was supraoptimal causing a reduction in both 
percentage of shoot regeneration and their number per explant. (Table 2, Fig. 1B,C). Addition of $4.44 \mu \mathrm{MBA}$ and $2.68 \mu \mathrm{M}$ NAA the culture produced green

Table 1. Influence of various concentrations and combinations of 2, 4-D, NAA, and BAP on callus induction from node and leaf explants of $S$. rebaudiana.

\begin{tabular}{llllcc}
\hline \multicolumn{3}{c}{ Growth regulators $(\mu \mathrm{M})$} & & & \multicolumn{2}{c}{$\begin{array}{c}\text { \% explants forming callus } \\
\text { from explant type }\end{array}$} \\
\cline { 1 - 2 } \cline { 5 - 6 } \cline { 5 - 6 } $2,4 \mathrm{D}$ & NAA & BA & & Node & Leaf \\
\hline 0.0 & 0.0 & 0.0 & & Nil & Nil \\
2.26 & 0.0 & 2.22 & & $40.0 \pm 0.0^{\mathrm{a}}$ & $46.7 \pm 2.8^{\mathrm{a}}$ \\
4.52 & 0.0 & 2.22 & & $61.6 \pm 5.7^{\mathrm{c}}$ & $50.0 \pm 5.0^{\mathrm{ab}}$ \\
11.31 & 0.0 & 2.22 & & $45.0 \pm 5.0^{\mathrm{ab}}$ & $80.0 \pm 5.0^{\mathrm{c}}$ \\
22.62 & 0.0 & 2.22 & & $40.0 \pm 0.0^{\mathrm{a}}$ & $63.3 \pm 7.6^{\mathrm{b}}$ \\
0.0 & 2.69 & 2.22 & & $46.7 \pm 2.8^{\mathrm{ab}}$ & $55.0 \pm 5.0^{\mathrm{ab}}$ \\
0.0 & 5.37 & 2.22 & & $46.7 \pm 2.8^{\mathrm{ab}}$ & $60.0 \pm 5.0^{\mathrm{ab}}$ \\
0.0 & 13.43 & 2.22 & & $48.3 \pm 2.8^{\mathrm{b}}$ & $55.0 \pm 5.0^{\mathrm{ab}}$ \\
0.0 & 26.85 & 2.22 & & $55.0 \pm 5.0^{\mathrm{bc}}$ & $50.0 \pm 5.0^{\mathrm{ab}}$ \\
\hline
\end{tabular}

Explants were cultured on MS supplemented with 2, 4-D, NAA, or BAP. Data were recorded after 40 days of culture. Results represent mean \pm SD of six replicated experiments. Values denoted by different letters differ significantly at $\mathrm{p}<0.05$ level .

callus and in other concentration of BA along with NAA swelled, turned brown and failed to grow later. Callus transferred to MS containing BA alone (1.11 $8.88 \mu \mathrm{M}$ ) grew vigorously and developed into green compact structures (Table 2) which ultimately turned brown and failed to develop in to normal shoots. Callus transferred to NAA did not show any development or growth but the callus showed light green in colour. The regenerated shoots attained a height of about $5.6 \mathrm{~cm}$ in about 28 days. Though addition of NAA in lower concentrations (1.34 and $2.67 \mu \mathrm{M})$ along with BA $(4.44 \mu \mathrm{M})$ increased the shoot length, whereas higher concentrations do not have positive influence on shoot length. An earlier report on the callus initiation from foliar discs and its regeneration of plant from cell suspension culture of Stevia rebaudiana also reported the production of shoot buds on (Linsmaier and Skoog 1965) macro-, micro, nutrients, vitamins (Nitsch 1969) medium supple-mented with NAA and Kn. However, the results reported the development of plantlets through cell suspension culture and also using hormone intervention during two stages (Ferreira and Handro 1988). On the other hand, use of BAP and NAA for shoot development from callus observed in this study is in agreement with earlier reports on organogenesis in dicotyledon plants (Asamenew and Narayanaswamy 2000, Dhar and Joshi 2005, Hee et al. 

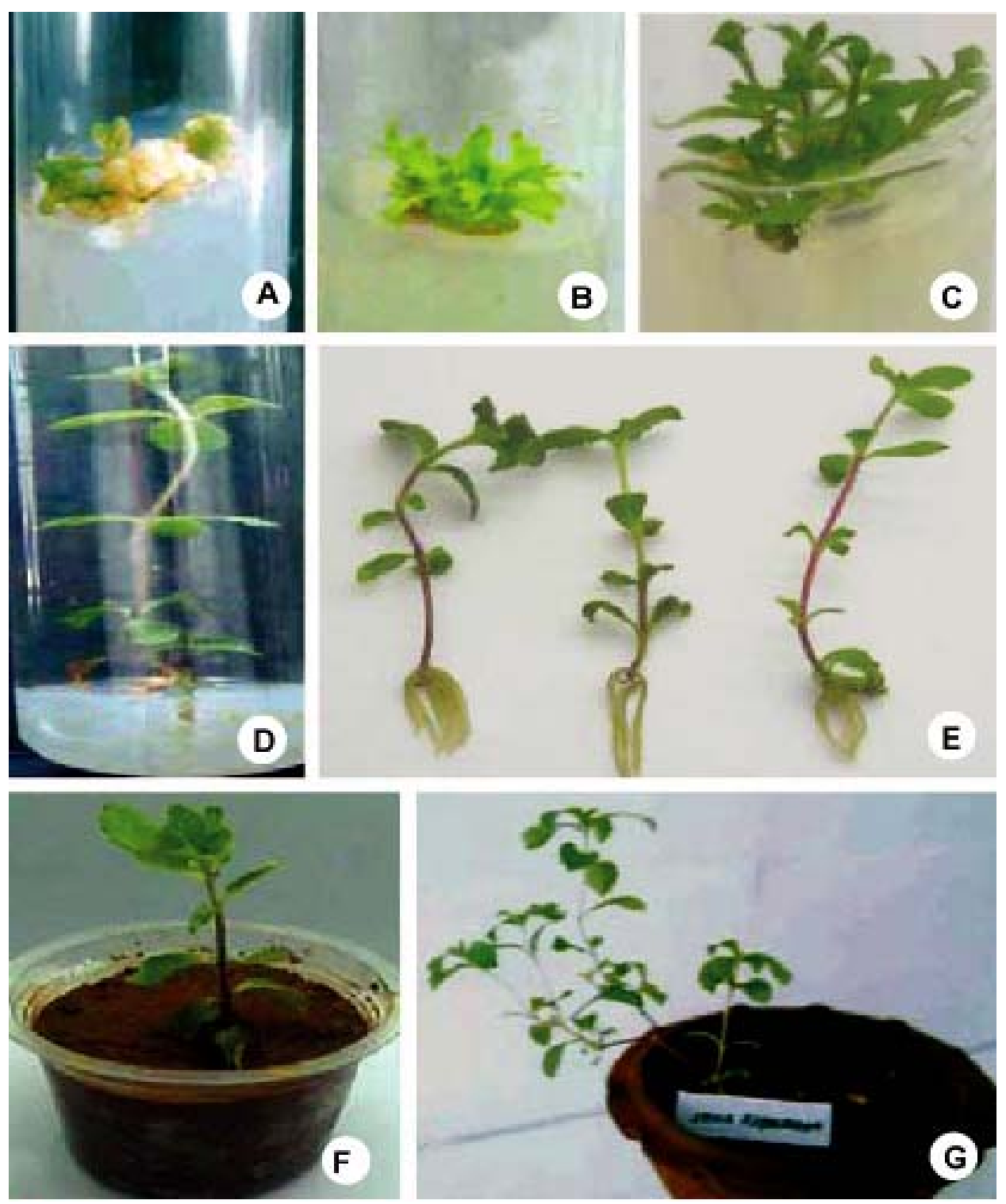

Fig. 1. Regeneration of multiple shoots from leaf derived callus of Stevia rebaudiana. (A) Callus initiation of leaf explant. (B \& C) Proliferation of multiple shoots from leaf derived callus at day 28. (D) A rooted Stevia rebaudiana plant after 25 days. (E) Three well established rooted plants. (F) Well established plants successfully transplanted to the paper cups. (G) Plants transferred to pots.

2006, Kumari and Pardhasaradhi 1992, Rev and Mroginski 1996, Roche et al. 1986). Hence, the synergistic combination of auxin and cytokinin on organogenic differentiation has been well established in several systems (Koroch 2002, Pereira et al. 2000, Pretto and Santarém 2000, Thomas and Puthur 2004, Xie and Hong 2001). 
Table 2. Morphogenic effect of BAP and NAA on leaf derived callus of Stevia rebaudiana.

\begin{tabular}{|c|c|c|c|c|c|}
\hline $\begin{array}{c}\text { BA } \\
(\mu \mathrm{M})\end{array}$ & $\begin{array}{l}\text { NAA } \\
(\mu \mathrm{M})\end{array}$ & $\begin{array}{l}\text { Response } \\
(\%)\end{array}$ & $\begin{array}{l}\text { Av. No. of } \\
\text { shoots }\end{array}$ & $\begin{array}{l}\text { Av. shoot } \\
\text { length }(\mathrm{cm})\end{array}$ & $\begin{array}{l}\text { Morphogenic } \\
\text { response }\end{array}$ \\
\hline 2.22 & 0.0 & 0.0 & 0.0 & 0.0 & Green nodular structures \\
\hline 4.44 & 0.0 & 0.0 & 0.0 & 0.0 & " \\
\hline 6.66 & 0.0 & 0.0 & 0.0 & 0.0 & Calli turned pale brown \\
\hline 8.88 & 0.0 & 0.0 & 0.0 & 0.0 & " \\
\hline 0.0 & 0.54 & 0.0 & 0.0 & 0.0 & No growth \\
\hline 0.0 & 1.34 & 0.0 & 0.0 & 0.0 & " \\
\hline 0.0 & 2.69 & 0.0 & 0.0 & 0.0 & $"$ \\
\hline 0.0 & 5.37 & 0.0 & 0.0 & 0.0 & $"$ \\
\hline 2.22 & 0.54 & 0.0 & 0.0 & 0.0 & $\begin{array}{l}\text { Tissue enlarged but failed } \\
\text { to grow further }\end{array}$ \\
\hline 2.22 & 1.34 & 0.0 & 0.0 & 0.0 & " \\
\hline 2.22 & 2.69 & 0.0 & 0.0 & 0.0 & $"$ \\
\hline 2.22 & 5.37 & 0.0 & 0.0 & 0.0 & $"$ \\
\hline 4.44 & 0.54 & $50.0 \pm 5.0^{\mathrm{ab}}$ & $6.3 \pm 1.1^{\mathrm{a}}$ & $2.6 \pm 0.1^{b}$ & Small green shoots \\
\hline 4.44 & 1.34 & $80.0 \pm 5.0^{c}$ & $14.0 \pm 1.0^{\mathrm{b}}$ & $5.6 \pm 0.1^{\mathrm{d}}$ & Well developed green shoots \\
\hline 4.44 & 2.69 & $55.0 \pm 5.0^{\mathrm{b}}$ & $7.0 \pm 1.0^{\mathrm{a}}$ & $3.0 \pm 0.1^{\mathrm{c}}$ & Small green shoots \\
\hline 4.44 & 5.37 & $40.0 \pm 5.0^{\mathrm{a}}$ & $5.3 \pm 1.1^{\mathrm{a}}$ & $1.8 \pm 0.1^{\mathrm{a}}$ & " \\
\hline 6.66 & 0.54 & 0.0 & 0.0 & 0.0 & Calli turned brown \\
\hline 6.66 & 1.34 & 0.0 & 0.0 & 0.0 & $"$ \\
\hline 6.66 & 2.69 & 0.0 & 0.0 & 0.0 & $"$ \\
\hline 6.66 & 5.37 & 0.0 & 0.0 & 0.0 & $"$ \\
\hline 8.88 & 0.54 & 0.0 & 0.0 & 0.0 & $"$ \\
\hline 8.88 & 1.34 & 0.0 & 0.0 & 0.0 & $"$ \\
\hline 8.88 & 2.69 & 0.0 & 0.0 & 0.0 & Growth inhibition \\
\hline 8.88 & 5.37 & 0.0 & 0.0 & 0.0 & " \\
\hline
\end{tabular}

Data were recorded after 28 days of culture. Results represent mean \pm SD of six replicated experiments. Values denoted by different letters differ significantly at $\mathrm{p}<0.05$ level.

Individual shoots from a multiple shoot mass were separated after 28 days transferred to half strength of MS supplemented with $2.46 \mu \mathrm{M}$ IBA (Table 3). In all media, roots appeared after one to two weeks and after 25 days, roots were well developed (Fig. 1 D,E). The maximum rooting response achieved on medium supplemented only with $2.46 \mu \mathrm{M}$ IBA was $100 \%$, with an average of 7.3 \pm 0.25 roots per shoot (Table 3 ). Though lower concentration of IBA produced 
significantly higher rooting and root length, higher concentration of IBA did not produce results as expected. The observation on the reduction of MS salts strength to one half to enhance the rooting frequency is in agreement with earlier finding in S. rebaudiana (Sivaram and Mukundan 2003).

Table 3. Rooting response of in vitro derived S. rebaudiana shoots.

\begin{tabular}{lccc}
\hline IBA $(\mu \mathrm{M})$ & \% response & Roots/shoot & Root length $(\mathrm{cm})$ \\
\hline 0.49 & $30.0 \pm 5.0^{\mathrm{a}}$ & $4.2 \pm 0.20^{\mathrm{a}}$ & $3.2 \pm 0.2^{\mathrm{a}}$ \\
0.98 & $41.7 \pm 7.6^{\mathrm{a}}$ & $4.3 \pm 0.17^{\mathrm{a}}$ & $3.3 \pm 0.3^{\mathrm{ab}}$ \\
2.46 & $100 \pm 0.0^{\mathrm{c}}$ & $7.3 \pm 0.25^{\mathrm{c}}$ & $5.5 \pm 0.2^{\mathrm{c}}$ \\
4.92 & $55.0 \pm 5.0^{\mathrm{b}}$ & $5.3 \pm 0.12^{\mathrm{b}}$ & $3.8 \pm 0.1^{\mathrm{b}}$ \\
12.30 & $36.6 \pm 2.8^{\mathrm{a}}$ & $5.0 \pm 0.10^{\mathrm{b}}$ & $3.1 \pm 0.1^{\mathrm{a}}$ \\
\hline
\end{tabular}

Data were recorded after 25 days. Results represent mean \pm Sd of six replicated experiments. Values denoted by different letters differ significantly at $\mathrm{p}<0.05$ level.

Cent per cent plantlet survival was seen after hardening of the regenerated Stevia rebaudiana in red soil, vermiculite, and farmyard manure $(1: 1: 1)$ for three weeks. However, the rate decreased as some of the plants died over the next four to six weeks on transfer to soil. It was observed that gradual acclimatization of in vitro grown plants to the external environment is most essential for Stevia. Ninety per cent of the plants transferred to pots survived and resumed growth (Fig. 1F, $\mathrm{G})$. There was no detectable variation among the acclimatized plants with respect to morphological and growth characteristics compared to each other and to the control plants of Stevia rebaudiana. In conclusion, the results reported here demonstrated the ability to regenerate whole plants of Stevia rebaudiana from leaf explants. Significant numbers of shootlets were produced in the present study through an intervening callus phase with all regenerates showing normal phenotypes. This is the first report describing callus-mediated regeneration of Stevia rebaudiana from leaf explants and describes a rapid and simple protocol to obtain large numbers of plantlets within a short period. The authors estimate that more than 50,000 plantlets could be produced within five subcultures from the leaf callus explants. Further work to study the genetic fidelity and phytochemical availability is underway.

\section{Acknowledgement}

The author (BJ) thanks the Principal and Dr. C. R. Bojan, Head of the Department of Botany, Pachaiyappa's College for providing Laboratory facilities and encouragement for this work. 


\section{References}

Asamenew MT and Narayanaswamy P (2000) Induction of callus and plant regeneration in Coleus forskohlii Briq. Jour. Appl. Hort. 2: 28-30.

Baskaran P and Jayabalan N (2005) An efficient micropropagation system for Eclipta alba a valuable medicinal herb. In vitro Cellular and Developmental Biology - Plant. 41: 532-539.

Dhar U and Joshi M (2005) Efficient plant regeneration protocol through callus for Saussurea obvallata (DC.) Edgew. (Asteraceae): effect of explant type, age and plant growth regulators. Plant Cell Reports 24: 195-200.

Ferreira CM and Handro W (1987) Production and maintenance and plant regeneration from cell suspension cultures of Stevia rebaudiana (Bert.) Bertoni. Plant Cell Reports 7: 123-126.

Ferreira CM and Handro W (1988) Micropropagation of Stevia rebaudiana through leaf explants from adult plants. Planta Medica 54: 157-160.

Fujita H and Edahiro T (1979) Steviasüßstoffe, Sicherheit und Verwendung Shokuhin Kogyo (Food Industry, Tokyo). 22: 66-72.

Geuns JMC (2004) Review: The safety of stevioside used as a sweetener. pp. 85-127 In: Proc. first symposium on the Safety of Stevioside. Geuns, J.M.C. and Buyse, J., Eds. Kuleuven, 2004. Euprint Editions ISBN 9074253024, pp. 127.

Goettemoeller J and Ching A (1999) Seed germination in Stevia rebaudiana.In: J. Janick (ed.), Perspectives on new crops and new uses. ASHS Press, Alexandria, VA, pp. 510511.

Hee WT, Hou SW and Wang CY (2006) Callus induction and high-frequency plant regeneration from hypocotyl and cotyledon explants of Arctium lappa L. In Vitro Cellular and Developmental Biology - Plant. 42: 411-414.

Ishima N and Katayama O (1986) Sensory evaluation of stevioside as a sweetener. Rep. Natl. Food Resp. Inst. 31: 80-85.

Janarthanam, B and Kanimozhi J (2005) In vitro study on Stevia rebaudiana Bertoni and its active compounds. National symposium on Path to Health - Biotechnology Revolution in India. Anna University, Chennai, 24-26 November.

Koroch A, Kapteyn J, Juliani HR and Simon JE (2002) In vitro regeneration and Agrobacterium transformation of Echinacea purpurea leaf explants. In: J. Janick and A. Whipkey (eds.), Trends in new crops and new uses. ASHS Press, Alexandria, VA. p. 522-526.

Kumari N and Pardhasaradhi P (1992) Regeneration of plants from callus cultures of Origanum vulgare L. Plant Cell Reports 11: 476-479.

Linsmaier EM and Skoog F (1965) Organic growth factor requirements of tobacco tissue culture. Physiol. Plant. 18: 100-127.

Nabors LO and Gelardi RC (1991) Alternative Sweeteners, vol. 2. Marcel Dekker, Inc.: NewYork. 157-171.

Nitsch JP (1969) Experimental androgenesis in Nicotiana. Phytomorph. 82: 389-404. 
Patil V, Reddy PS, Ashwini KS, Purushotham MG, Prasad TG and Udayakumar M (1996) In Vitro multiplication of Stevia rebaudiana. Curr Sci. 70: 960.

Pereira AM, Bertoni BW, Appezzato-da-Glória B, Araujo ARB, Januário AH Lourenco MV and Franca SC (2000) Micropropagation of Pothomorphe umbellate via direct organogenesis from leaf explants. Plant Cell Tiss. Org. Cult. 60: 47-53.

Pretto FR and Santarém ER (2000) Callus formation and plant regeneration from Hypericum perforatum leaves. Plant Cell Tiss. Org. Cult. 62:107-113.

Rev HY and Mroginski LA (1996) Regeneration of plants from callus tissue of Aeschynomene spp. (Leguminosae) Plant Cell Tiss. Org. Cult. 45: 185-190.

Roche MV, Luis AR and Moreno V (1986) Callus Formation, Plant Regeneration and Clonal Propagation in Vitro of Gynura aurantiaca. Plant Cell Physiol. 27: 61-66.

Russell L M (1979) Regeneration of whole plants from callus culture of diverse genetic lines of Pisum sativum L. Planta. 146: 243- 244.

Sakaguchi M and Kan T (1982) Japanese researches on Stevia rebaudiana (Bert.) Bertoni and stevioside. Ci Cult. 34: 235-248.

Sivaram L and Mukundan U (2003) In vitro culture studies on Stevia rebaudiana. In vitro Cell Development Biol. - Plant. 39: 520-523.

Soejarto DD, Compardre CM, Medon PJ, Kamath SK and Kinghorn AD (1983) Potential sweetening agents of plant origin II Field search for sweet tasting Stevia species. Econ. Bot. 37: 71-75.

Tamura Y Nakamura S Fukui H and Tabata M (1984) Clonal propagation of Stevia rebaudiana Bertoni by stem-tip culture. Plant Cell Reports 3: 183-185.

Tanaka O (1982). Steviol Glycosides; new natural sweeteners. Trends in Analytical Chemistry 1: 246-248.

Thomas TD and Puthur JT (2004) Thidiazuron induced high frequency shoot organogenesis in callus from Kigelia pinnata L. Acad. Sini. 45: 307-313

Uddin MS, Chowdharry MSH, Haque Khan MM, Uddin MMB, Ahmed R and Azizul B (2006) In vitro propagation of Stevia rebaudiana Bert. in Bangladesh. African Journal of Biotechnology 5: 1238.

Xie DY and Hong Y (2001) Regeneration of Acacia mangium through somatic embryogenesis. Plant Cell Reports 20: 34-40. 